\title{
Developing a New Model of Resistance-based Strength Train and Its Effects on Junior Athletes' Tennis Serve Performance
}

\author{
Rina Ambar Dewanti ${ }^{1, *}$, Beltasar Tarigan ${ }^{1}$, Dian Budiana ${ }^{1}$, Yudy Hendrayana ${ }^{1}$, Lutfi Nur ${ }^{2}$ \\ ${ }^{1}$ Department of Sports Education, School of Postgraduate Studies, Universitas Pendidikan Indonesia, 40154, Bandung, Indonesia \\ ${ }^{2}$ Department of Elementary Teacher Education, Tasikmalaya Campus, Universitas Pendidikan Indonesia, 40154, Bandung, Indonesia
}

Received July 1, 2020; Revised September 17, 2020; Accepted September 29, 2020

\section{Cite This Paper in the following Citation Styles}

(a): [1] Rina Ambar Dewanti, Beltasar Tarigan, Dian Budiana, Yudy Hendrayana, Lutfi Nur , "Developing a New Model of Resistance-based Strength Train and Its Effects on Junior Athletes' Tennis Serve Performance," International Journal of Human Movement and Sports Sciences, Vol. 8, No. 5, pp. 229 - 234, 2020. DOI: 10.13189/saj.2020.080510.

(b): Rina Ambar Dewanti, Beltasar Tarigan, Dian Budiana, Yudy Hendrayana, Lutfi Nur (2020). Developing a New Model of Resistance-based Strength Train and Its Effects on Junior Athletes' Tennis Serve Performance. International Journal of Human Movement and Sports Sciences, 8(5), 229 - 234. DOI: 10.13189/saj.2020.080510.

Copyright $\bigcirc 2020$ by authors, all rights reserved. Authors agree that this article remains permanently open access under the terms of the Creative Commons Attribution License 4.0 International License

\begin{abstract}
This study was aimed at developing a new model of resistance-based strength training for junior tennis athletes and examining its effectiveness on their serve performance compared to traditional model of training. It is a Research and Development study focusing on developing, validating, revising, and testing the model of training. In testing phase, effectiveness test was accomplished to examine the effectiveness of the new training model and compared to the effectiveness of the traditional model. There were 60 junior athletes contributing to this study. The data were gathered by distributing questionnaires to reveal the convenience and attractiveness of the model developed and using Collang Smart Tennis Racket Sensor Tracker Motion Analyzer to reveal the tennis athletes' serve performance. The data were analyzed by employing descriptive statistic and t-test. In terms of convenience and attractiveness, this study revealed that the use of resistance training for junior tennis athletes showed good results. T-test proved that this new model was more effective in improving players' serve speed compared to traditional model was. Thus, researchers concluded that the new model of resistance-based training can be implemented to increase tennis junior players' serve speed.
\end{abstract}

Keywords Junior Athletes, Resistance, Strength Training Model, Tennis

\section{Introduction}

Tennis is a popular sport and favored by people from all levels of society without being restricted by age, gender, social status, and some other backgrounds. This branch of sport keeps developing that can be seen by the number of annual tennis tournaments conducted both at national and international levels. Obviously, this phenomenon has impacted on intense competition among the athletes to participate in the tournaments in which, nowadays, professional and semi-professional sport gives slight potential for them to win; and, it becomes an intense pressure for the couches and athletes [1-3]. Therefore, the athletes should be well-prepared and well-trained to compete in every tournament by performing numerous training programs designed to achieve the targets.

To develop the athletes' skill and performance, numerous studies have examined various models of training such as by giving video modelling and imaging training that was empirically proved to have impacts on performance of tennis serve of 9-to 12-year old children [4], a different approach to the design of an effective strength training program in modern tennis conducted by [5] was proved to be effective to enhance basic and specific 
strength efficiently and be able to minimize and prevent injury. It means that the development of models of training or some various approaches should be done to improve the athletes' performance as the needs. So, strength performance is a crucial element for athletes that it needs strategies to develop a strength training for tennis players [6].

It is assumed that children should not be given strenuous training as it puts extreme stress on muscle growth that possibly harms their muscle [7]. However, this assumption has not been proved. Previous research showed various training modalities such as weight machines, free weights, body-weight exercises, sports-conditioning drills, with different formula set and repetition could adequately stimulate the enhancement of strength development for children $[8,9]$. By supervision and proper training program design, strength training can be beneficial and effective for children and youths' growth as long as it is supervised and performed carefully, and it will not cause injury.

One of strength development trainings for children and adolescents is resistance training. This type of training has been used by many couches because it could enhance strength and increase body composition, reduce fat mass, increase lean body mass, increase muscle strength and endurance, increase bone mineral density, and increase blood lipid profile [12,13]. In addition, this model of training can improve flexibilities and stimulate the increase of proprioception due to the increase of the activity of motor units recruitment that activates golgi tendon organ and muscle spindle [13]. Nevertheless, specifically, the implementation of resistance model of training to improve serve performance of tennis players has not been examined massively.

This study focused on the development of an approach of strength training model based on resistance that is unchallenging and interesting for children and adolescents. With this concept, it is expected that it would implicitly motivate them who usually get bored with monotonous strength training [14,15]. To examine the effects, researchers used Collang Smart Tennis Racket Sensor Tracker Motion Analyzer to analyse the athletes' serve speed. The use of this technology was expected to be validly able to examine the effects of the model of strength training based on resistance on measurable athletes' serve result. Some researchers, has recommended the utilization of technology in sport to help coaches evaluate their athletes' performance [16,17]. Moreover, this study was aimed at developing a new model of training to train athletes' strength based on resistance that was unchallenging and interesting for junior tennis athletes and to examine the effectiveness of the model of training compared to traditional models of training.

\section{Materials and Methods}

This is a Research and Development study conducted to create a certain product and examine its effectiveness $[18,19]$. This study developed a product in form of a model of strength training based on resistance for junior tennis athletes. Its procedure was begun by developing, validating, and revising and testing the model of training.

Draft of the design of the model of resistance-based strength training was created into 24 models. These models were discussed and validated by 3 coaches with national level of coaching license and with more than 2-year coaching experience. After validating, 18 models of resistance-based strength training were ready to be tested. These designs were made based on 3 major elements, namely: exercise model for the leg as shown in figure 1, exercise model for core stability as shown in figure 2 and exercise model for arm as shown in figure 3.

There were three stages in testing the model of the training, namely: small-scale testing with 20 samples (athletes), large-scale testing with 40 samples (athletes), and effectiveness testing by comparing experimental group given the treatment using resistance-based model of strength training to control group. In effectiveness testing, experimental group did train for 12 meetings (60 minutes for each meeting) by performing resistance-based strength training.

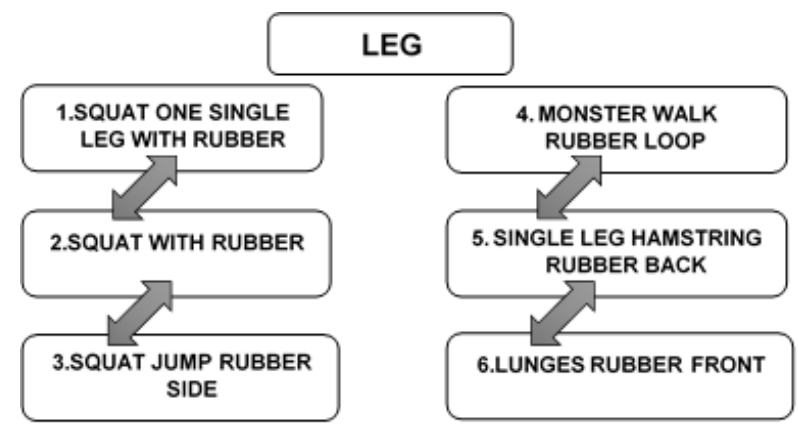

Figure 1. A Design of Resistance-Based Strength Training for Leg

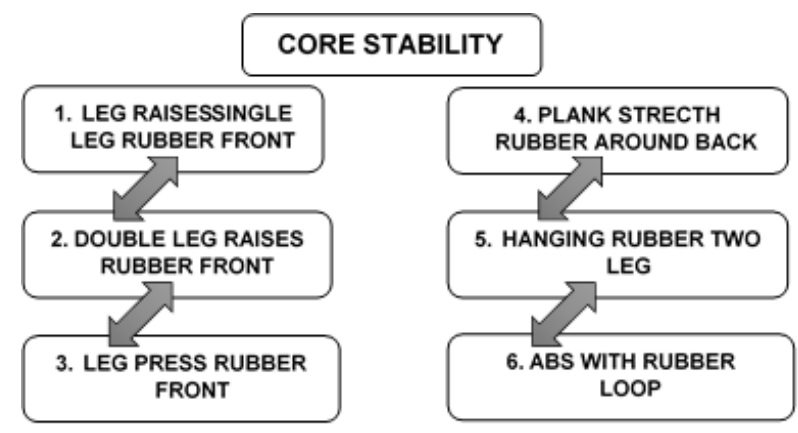

Figure 2. A Design of Resistance-Based Strength Training for Core Stability 


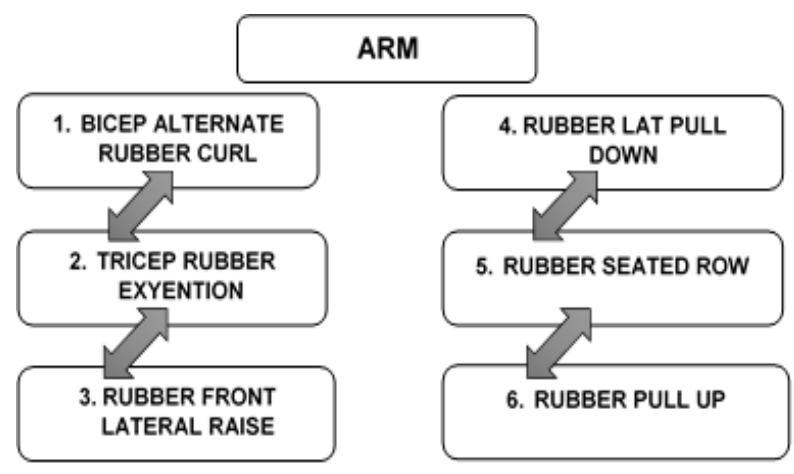

Figure 3. A Design of Resistance-Based Strength Training for Arm

Data of small - scale and large - scale tests were collected to investigate the level of easiness or convenience and attractiveness of the model and then analyzed by descriptive statistic. Meanwhile, data of effectiveness testing were collected by using instrument Collang Smart Tennis Racket Sensor Tracker Motion Analyzer [20] to measure serve speed. Next, t-test was conducted to examine its effectiveness between experimental group and control group.

\section{Result}

\subsection{Result of Small-scale and Large-scale Tests}

For small-scale test, 20 samples filled a questionnaire about convenience and comfort; while, for large-scale test, 40 athletes answered a questionnaire consisting of 18 questions regarding the use of resistance-based strength training model. The result is presented in the table 1 below.

Referring to the Table 1, for the result of small-scale test, the aspect of convenience reaches 325 from a total score 360 with a percentage of $90.27 \%$; while, the aspect of comfort obtained 326 from 360 with a percentage of $90.55 \%$. It indicates that resistance-based strength training model tested in small-scale could be categorized into good category. Next, for the result of large-scale test, the aspect of convenience gained 650 and aspect of comfort reached 659 from a total score 720 with achievement percentages of $90.27 \%$ and $91.52 \%$, respectively. It indicates that the small-scale and large-scale tests show a good result meaning that the training model could be proceeded to the next stage, namely effectiveness testing conducted by comparing the model of resistance-based strength training to traditional training model.

Table 1. The result of small-scale and large-scale testing

\begin{tabular}{cccccc}
\hline & Aspect & Score Results & Score Maximal & $\mathbf{\%}$ & Explanation (Category) \\
\hline $\begin{array}{c}\text { Small-scale } \\
\text { test }\end{array}$ & Convenience & 325 & 360 & 90.27 & good \\
& Comfort & 326 & 360 & 90.55 & good \\
$\begin{array}{c}\text { Large-scales } \\
\text { test }\end{array}$ & Convenience & 650 & 720 & 90.27 & good \\
& Comfort & 659 & 720 & 91.52 & good \\
\hline
\end{tabular}




\subsection{Result of Effectiveness Test}

In accomplishing effectiveness test, this study used t-test to examine the increase of the samples ' performance of tennis serve. The result of t-test for experimental and control groups and the difference between the two groups are presented in the table 2 below.

Table 2. Result of t-test of experimental and control groups

\begin{tabular}{|c|c|c|c|c|}
\hline Group & Average & $T_{\text {value }}$ & $t_{\text {table }}$ & $\mathbf{p}$ \\
\hline Pretest Experiment & 136.87 & \multirow{2}{*}{22.00} & \multirow{2}{*}{1.71} & \multirow{2}{*}{0.000} \\
\hline Posttest Experiment & 159.20 & & & \\
\hline Pretest Control & 132.60 & \multirow{2}{*}{19.54} & \multirow{2}{*}{1.71} & \multirow{2}{*}{0.000} \\
\hline Posttest Control & 139.33 & & & \\
\hline \multicolumn{2}{|c|}{ Experiment vs Control } & 10.50 & 2.47 & 0.000 \\
\hline
\end{tabular}

In the Table 2, the average results of pretest for experimental and control groups are 136.87 and 159.20, respectively, with a difference of 22.33 . T-test shows that t-value (22.00) is higher than t-table (1.71). it indicates that there was a significant difference between pre-test and post-test results; therefore, it can be said that the treatment of resistance-based strength training model could statistically improve junior tennis athletes' serve skill. The similar result was also released from control group with average scores of pretest and posttest are 132.60 and 139.33 , respectively, with a difference of 6.73 . T-test for control group also indicates that there was an effect of the use of traditional model of training on the improvement of athletes' serve skill proven by the higher value of $\mathrm{t}$-value than $\mathrm{t}$-table.

Although both tests showed positive impacts on increasing tennis athletes' serve performance, experimental group more significantly impacted than control group. It can be seen from the difference of $\mathrm{t}$-values between the experimental group and control group which are 10.50 and 2.47 , respectively. Therefore, the use of resistance-based strength training model was proven to be more effective in improving the performance of junior tennis athletes in serving than the use of traditional model was.

\section{Discussion}

This study was aimed at developing a new model of strength training based on resistance and examining its effectiveness compared to traditional training model. Accomplishing some stages in developing this model, there were 18 models of resistance training using rubber band. These models had been validated by the experts, tested through small - scale and large - scale tests and examined its effectiveness.

Considering the result of small - scale and large - scale tests, the experts, (i.e. the couches) suggested that to attract and facilitate athlete in implementing the model of training, it would be better to match the color of rubber band with the basic skill of the athletes. In addition, to conduct the training more effectively, it is recommended to increase the number of matrass and rubber band according to the number of the athletes. It is in line with the research result conducted by [21] revealing that an interesting training can increase an athlete's motivation to train so that the training process is not monotonous but still maintains the same essence to achieve the training targets optimally. After fulfilling the experts' advices, a large-scale test was conducted and there were no significant difficulties and problems encountered during the testing so that the model of resistance-based strength training can be applied in training program for tennis athletes.

The effectiveness test between the two groups revealed that experimental group showed better result than control group did. This result is supported by the result of previous research revealing that a training program based on resistance could enhance the average speed of tennis serve for adolescent [22]. Another study conducted by [23] added that the combination of resistance band training was effective to increase the jump height, arm strength, speed and agility. Basically, strength training uses the principle of progressive overload, forcing the body (muscles, tendons, bones, etc.) to adapt in order to release a greater energy [24], moreover, resistance-based strength training could stimulate athletic development, tolerate the demands of training and long-term competence, and escalate the effect of health enhancement over time that keeps maintaining until adulthood [25].

Youths, whether they are athletes or not, can be successful in increasing their power and health safely and comprehensively by participating in a program that is supervised effectively. Coaches play important roles in determining and ensuring technique, forms, proper training development and guarantying athlete's safety. Therefore, model of resistance-based strength training is safe to be implemented and beneficial for children. Strengthening the result, the model of resistance-based training was effective to enhance tennis serving skill foe children and adolescent [26]. The finding of this study is also supported by [27,28] stating that coaches took a part in managing training pattern and safety so that the model of resistance training could be practiced optimally. Resistance training was also effective to escalate speed and accuracy in tennis training program [29].

\section{Conclusions}

Researchers concluded that: firstly, the new model of strength training based on resistance was successfully developed into 18 models of training which were attractive and facilitative to be implemented and had been validated by the experts. Secondly, the model of resistance-based strength training had been tested to 
improve the performance of junior tennis athletes in doing serve more effectively than the conventional model did. Therefore, it is highly suggested for both coaches and athletes to implement this model in training in order to enhance tennis players' performance of serve. For further research, researchers recommended to examine other aspects related to strength to reveal the impacts in wider scope.

\section{REFERENCES}

[1] D. Birrer and G. Morgan, "Psychological skills training as a way to enhance an athlete's performance in high sports,” Scand. J. Med. Sci. Sports, vol. 20, pp. 78-87, 2010.

[2] G. Suna and M. Kumartasli, "Investigating Aerobic, Anaerobic Combine Technical Trainings' Effects on Performance in Tennis Players.," Univers. J. Educ. Res., vol. 5, no. 1, pp. 113-120, 2017.

[3] S. Yildiz, "Relationship between Functional Movement Screen and Athletic Performance in Children Tennis Players.," Univers. J. Educ. Res., vol. 6, no. 8, pp. $1647-$ 1651, 2018.

[4] F. L. Atienza, I. Balaguer, and M. L. García-Merita, "Video Modeling and Imaging Training on Performance of Tennis Service of 9- to 12-Year-Old Children," Percept. Mot. Skills, vol. 87, no. 2, pp. 519-529, Oct. 1998.

[5] M. A. Cardoso Marques, "Strength Training in Adult Elite Tennis Players," Strength Cond. J., vol. 27, no. 5, pp. 34-41, 2005.

[6] J. Fernandez-Fernandez, D. Sanz-Rivas, M. S. Kovacs, and M. Moya, "In-season effect of a combined repeated sprint and explosive strength training program on elite junior tennis players," J. Strength Cond. Res., vol. 29, no. 2, pp. 351-357, 2015.

[7] A. D. Faigenbaum, "Strength training for children and adolescents," Clin. Sports Med., vol. 19, no. 4, pp. 593-619, 2000 .

[8] L. D. Isaacs, R. Pohlman, and B. Craig, "Effects of resistance training on strength development in prepubescent females," Med. Sci. Sport. Exerc., vol. 26, no. 5, p. S210, 1994.

[9] A. D. Faigenbaum, R. S. Lloyd, J. MacDonald, and G. D. Myer, "Citius, Altius, Fortius: beneficial effects of resistance training for young athletes: narrative review," Br. J. Sports Med., vol. 50, no. 1, pp. 3-7, 2016.

[10] M. Behringer, A. vom Heede, Z. Yue, and J. Mester, "Effects of resistance training in children and adolescents: a meta-analysis," Pediatrics, vol. 126, no. 5, pp. e1199-e1210, 2010.

[11] J. D. Kingsley, V. McMillan, and A. Figueroa, "The effects of 12 weeks of resistance exercise training on disease severity and autonomic modulation at rest and after acute leg resistance exercise in women with fibromyalgia," Arch. Phys. Med. Rehabil., vol. 91, no. 10, pp. 1551-1557, 2010.

[12] S. P. Bird, F. Marino, S. P. Bird, K. M. Tarpenning, and F. E.
Marino, "Designing Resistance Training Programmes to Enhance Muscular Fitness,” Sport. Med., vol. 35, no. 10, pp. 841-851, 2005.

[13] D. Behm and J. C. Colado, "The effectiveness of resistance training using unstable surfaces and devices for rehabilitation,”Int. J. Sports Phys. Ther., vol. 7, no. 2, p. 226, 2012.

[14] A. Rokhayati, L. Nur, E. Elan, and G. Gandana, "Tactical Approach to Increase Motivation for Learning Students on Physical Education Teaching in Primary Schools," in IOP Conference Series: Materials Science and Engineering, 2017.

[15] L. Nur, P. M. Setiadi, Y. Kusdinar, and A. A. Malik, "Electronic rubric for motivation in physical education," iOP Conf. Ser. J. Phys. Conf. Ser., 2019.

[16] L. Nur, A. Suherman, and H. Subarjah, "The Use of Global Positioning System (GPS) Polars to Determine Motion Intensity,” J. Eng. Sci. Technol., vol. 14, no. 4, pp. 2132 2139, 2019.

[17] I. Reade, W. Rodgers, and K. Spriggs, "New Ideas for High Performance Coaches: A Case Study of Knowledge Transfer in Sport Science," Int. J. Sports Sci. Coach., vol. 3, no. 3, pp. 335-354, 2008.

[18] M. D. Gall, J. P. Gall, and W. R. Borg, Educational Research, 7th ed. United States: Pearson Edition, Inc, 2003.

[19] A. A. Malik, “'Ular Tangga Olahraga' Media Permainan Edukatif untuk Olahraga dengan Menggunakan Sistem Sirkuit Training bagi Siswa Kelas X SMA Negeri Ajibarang Tahun 2013," Act. J. Phys. Educ. Sport. Heal. Recreat., vol. 2, no. 10, pp. 630-636, 2013.

[20] D. Leung, "Coollang Smart Tennis Sensor Helps Players Track Improvement," 2017. [Online]. Available: https://www.sporttechie.com/coollang-smart-tennis-sensorhelps-players-track-improvement/. [Accessed:30-Mar-2020 ].

[21] G. Jones, S. Hanton, and D. Connaughton, "A framework of mental toughness in the world's best performers," Sport Psychol., vol. 21, no. 2, pp. 243-264, 2007.

[22] M. Behringer, S. Neuerburg, M. Matthews, and J. Mester, "Effects of two different resistance-training programs on mean tennis-serve velocity in adolescents," Pediatr. Exerc. Sci., vol. 25, no. 3, pp. 370-384, 2013.

[23] A. Agopyan, N. Ozbar, and S. N. Ozdemir, "Effects of 8 -week Thera-Band training on spike speed, jump height and speed of upper limb performance of young female volleyball players," Int. J. Appl. Exerc. Physiol., vol. 7, no. 1, pp. 63 76, 2018.

[24] V. M. Zatsiorsky, W. J. Kraemer, and A. C. Fry, Science and practice of strength training. Human Kinetics, 2020.

[25] U. Granacher et al., "Effects of resistance training in youth athletes on muscular fitness and athletic performance: a conceptual model for long-term athlete development," Front. Physiol., vol. 7, p. 164, 2016.

[26] V. G. Payne, J. R. Morrow Jr, L. Johnson, and S. N. Dalton, "Resistance training in children and youth: a meta-analysis," Res. Q. Exerc. Sport, vol. 68, no. 1, pp. 80-88, 1997. 
[27] S. Dorsch, L. Ada, and D. Alloggia, "Progressive resistance training increases strength after stroke but this may not carry over to activity: a systematic review," J. Physiother., vol. 64, no. 2, pp. 84-90, 2018.

[28] O. Girard, J.-P. Micallef, and G. P. Millet, "Influence of restricted knee motion during the flat first serve in tennis," J.
Strength Cond. Res., vol. 21, no. 3, pp. 950-957, 2007.

[29] J. B. Mann, J. P. Thyfault, P. A. Ivey, and S. P. Sayers, "The effect of autoregulatory progressive resistance exercise vs. linear periodization on strength improvement in college athletes," J. strength Cond. Res., vol. 24, no. 7, pp. 1718 $1723,2010$. 